\title{
Borderline Resectable Malignant Neoplasm
}

National Cancer Institute

\section{Source}

National Cancer Institute. Borderline Resectable Malignant Neoplasm. NCI Thesaurus.

Code C157346.

A term that applies to a malignant neoplasm and refers to a continuum between resectable and locally advanced unresectable disease. 